\title{
Computerized Ophthalmic Diagnostic Testing: An Engineer Looks Back at Lessons Learned
}

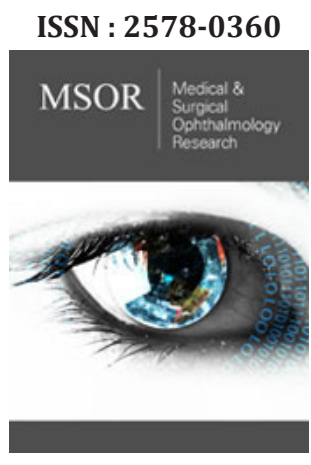

*Corresponding author: Harley R Myler, Professor of Electrical Engineering, Lamar University, USA

Submission: 漈 December 8, 2020

Published: 漹December 15, 2020

Volume 3 - Issue 1

How to cite this article: Harley R Myler Computerized Ophthalmic Diagnostic Testing: An Engineer Looks Back at Lessons Learned. Med Surg Ophthal Res. 3(1). MSOR. 000554. 2020.

DOI: 10.31031/MSOR.2020.03.000554

Copyright@ Harley R Myler, This article is distributed under the terms of the Creative Commons Attribution 4.0 International License, which permits unrestricted use and redistribution provided that the original author and source are credited.

\section{Harley R Myler*}

Professor of Electrical Engineering, Lamar University, USA

\section{Opinion}

Over thirty years ago and along with two other colleagues, one an ophthalmologist (MD), I invented a device that we called the Trophorometer a device to "measure tropias (manifest ocular misalignment) and phorias (latent deviation compensated for by the fusional reflex) to within one to two degrees" [1]. This was not my first foray as an engineer into the fascinating world of ophthalmology as I had designed and coded a system for the American Academy of Ophthalmology to allow practitioners to track and bill patients-this was a new concept back then and although I was well-paid as a consultant in the project, it really was not my passion. Since then, others have taken up patient database development and done a commendable job. My involvement in the design and construction of a proof-of-principle model of the Trophorometer was due to my expertise in computer vision. (Figure 1) (from the patent [1]) illustrates the basic concept of the device. Clinicians and anyone who has had a general eye exam will immediately recognize the architecture. The patient sits in front of the device and rests their chin on a rest and looks into the device. For our prototype we employed a bitebar and a head restraint because we had to have absolute fixation and no eye movement. We identified the pupil using a generalized Hough Transform [2] and achieved very good results. Our goal was to provide a rapid and inexpensive technique for screening children for strabismus. What we had not considered was the fact that the existing method of strabismus evaluation would make our invention a white elephant.

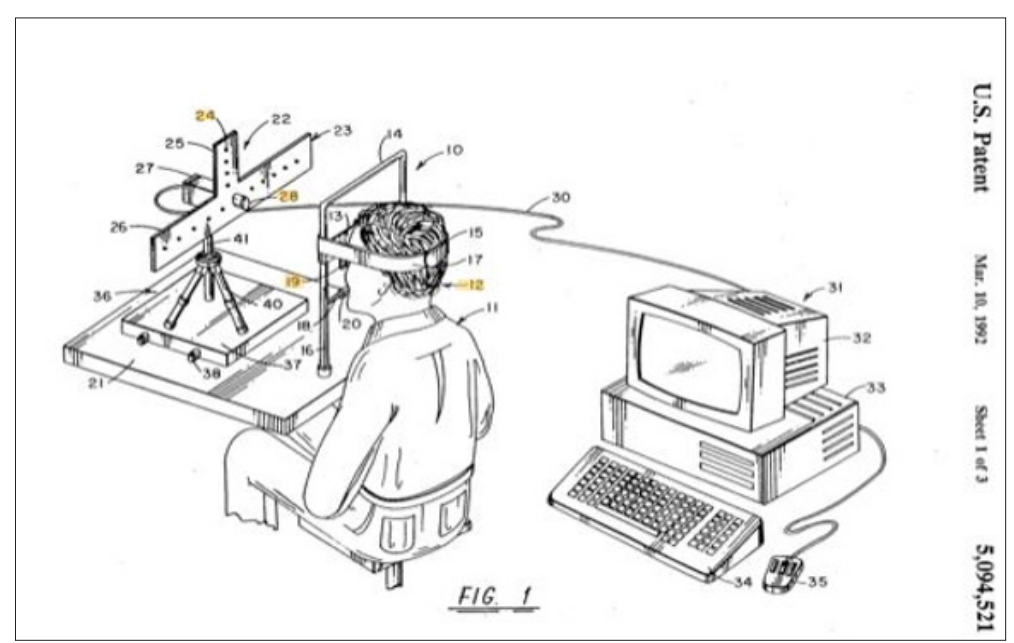

Figure 1: Design and construction of a proof-of-principle model of the Trophorometer.

Shortly after we patented our device, we consulted with a pediatric ophthalmologist to solicit his opinion as to the salability of our new device. He listened to our presentation, which included diagrams and data run from our instrument-and at this point I will add that one 
of our inventors had a somewhat severe and uncorrected lateral trope so he made an excellent subject for evaluating the device. The doctor then asked how much the machine would cost and we said in the neighborhood of $\$ 10 \mathrm{~K}$ in 1990 's dollars. Then he told us that no one would buy it. We were shocked and asked why given how automated and accurate our device was. He then explained that the way strabismus is measured is via a set of prisms, which he then showed us. A good set of prisms at the time ran roughly $\$ 400$ and they can be found on the Internet for significantly less than that. For any practice to invest in an instrument, the cost of said device would have to have a payback of three or four years and our instrument would not be cost effective as insurance companies would not pay for an exam with it given that the far less expensive prism exam was available. In fact, using prisms to evaluate strabismus exists to this day [3].

\section{Conclusion}

So, the moral of this story is that although a practitioner might have a good idea and also have access to colleagues with the requisite engineering skills to implement it, a major consideration is the ultimate marketability of the device. What we failed to do was look at what our Trophorometer would be replacing and that inexpensive set of prisms was not going to be dethroned.

\section{References}

1. Jolson Alfred S, Myler Harley R, Weeks A (1990) Apparatus for evaluating eye alignment. USA.

2. Duda RO, Hart PE (1972) Use of the hough transformation to detect lines and curves in pictures. Comm ACM 15(1): 11-15.

3. Antony J (2017) Prisms in clinical practice. Kerala J Ophthalmol 29(2): 79-85.

For possible submissions Click below: 